\title{
Maritime and island culture along the Kuroshio Current
}

\author{
Hyekyung Hyun \\ Center for Jeju Studies, South Korea \\ hhyun@jri.re.kr
}

\begin{abstract}
This guest editorial introduces Island Studies Journal's special thematic section on 'Maritime and island culture along the Kuroshio Current'. Although the islands of Far East Asia are typically studied individually or within national frameworks, they are in fact joined together by the Kuroshio Current, the world's second-large ocean current. Over the millennia, lifestyles, technologies, religions, and other cultural practices have spread along the Kuroshio Current, leading to the formation of a distinctive oceanic cultural sphere. In order to understand the island cultures within the region, one must take into account interconnections facilitated by the Kuroshio Current. This special thematic section includes papers on sea deity beliefs, pork food culture, and place naming on islands along the Kuroshio Current, with special focus on Jeju (Korea), Zhoushan Archipelago (China), Green Island (Taiwan), and the Ryūkyū Islands (Japan).
\end{abstract}

Keywords: Far East Asia, island culture, Kuroshio current, maritime culture

https://doi.org/10.24043/isj.60

(C) 2018 - Institute of Island Studies, University of Prince Edward Island, Canada.

The Kuroshio Current is the second largest ocean current after the Gulf Stream. The Kuroshio Current starts off along the east coast of Luzon, Philippines, passing through Taiwan, the Japanese Ryūkyū Islands, the East China Sea, Korea's Jeju Island, and along both the western and eastern coasts of mainland Japan. It joins the Oyashio Current to the east of Japan to become the North Pacific Current. In the regions where the Kuroshio Current flows, there are many scattered islands belonging to different countries. The Kuroshio Current connects and enables the cultural and technical interactions within the Far East Asia Pacific region. The influence of this current has created a degree of universality and specificity for island oceanic cultures in the region.

There have been exchanges of resources and people moving along this current since ancient times. Southern fish species such as anchovy, snapper, mackerel, Japanese Spanish mackerel, and whales migrate along the Kuroshio Current. There have been cultural and lifestyle exchanges among people who have travelled along this current. There has been a movement that created a shared civilization, what could be called the 'Kuroshio Road', including the sharing of fishing methods, marine culture, soy/miso culture, and marine deity culture. Such traces remain in the Kuroshio island culture to this day, and it has been argued that they should be understood as the marine cultural characteristics of the Kuroshio Current.

Far East Asia, where the Kuroshio Current flows, is subject to conflicts of interest on historical, political, and economic grounds among the various countries in the region (including the Philippines, Taiwan, Japan, Korea, and China). Such conflicts or tension have impeded interest in the idea of a shared maritime culture connected by the current. Maritime culture research has thus been limited to the coastal fisheries of each country and the study of lifestyles and livelihoods without understanding ocean currents and movements. As tensions regarding maritime borders have risen, it has become easy to miss the natural maritime cultural characteristics of the islands of the Kuroshio Current. 
It is only possible to gain a true understanding of a sea and its associated maritime or oceanic culture by excluding the concept of national borders. The contributors to this special thematic section of Island Studies Journal have all noted how resources, peoples, and cultures have moved along the ocean current in accordance with a marine ecological strategy. In recent years, there has been a scholarly movement to place greater attention on Far East Asian islands, where such ecological strategies have been maintained, leading to several workshops with researchers from Taiwan, China, Japan, and Korea. This research exchange has become an important starting point for establishing the foundations for a form of maritime culture research that is not bound by national borders. This has revealed traces of cultural and resource exchange among the islands of the Kuroshio Current going back many hundreds of years, including pigeon culture, fishery technology, maritime culture, and oceanic religious. The present special thematic section presents three papers that explore these issues, helping to introduce this discussion to English-language scholarship.

Heo and Lee (2018) investigate a specific marine faith on islands along the Kuroshio current. Given that few studies have been undertaken concerning oceanic rituals and sea deity beliefs along the Kuroshio Current, their research represents a starting point for this field. Heo and Lee find a special religious space in the Kuroshio oceanic cultural sphere. Islands that are distant from human settlements are recognized as birthplaces of deities and special religious spaces. Examples include Korea's Jeju Island, China's Zhoushan Archipelago, and Japan's Ryūkyū Islands. Heo and Lee research the manner in which the coming of deities from islands across the sea is a central characteristic of Kuroshio maritime faith. This is because the sea is recognized as a divine space. They also consider deities that are said to periodically visit islands, presiding over wind, food, and good fortune. Heo and Lee sketch out connections between sea deity traditions from islands throughout the region. Because Jeju is located on the final branch of the Kuroshio Current, it has absorbed diverse oceanic beliefs and elements of maritime culture from other islands. Through this paper's analysis, it is possible to understand the multilayered structure and historically conditioned nature of maritime culture along the Kuroshio Current.

Lee and Hyun (2018) write about the pork food culture of Luzon Island, Taiwan, Okinawa, and Jeju. They specifically investigate pork food culture in Okinawa and Jeju with respect to the formation of an ecological community, showing that pork food culture is important for island communities along the Kuroshio Current. This pork food culture is viewed as an environmentally conditioned factor in maintaining an island's ecological community. Lee and Hyun examine Okinawa's and Jeju's breeding spaces for dung-eating pigs, butchering, distribution of pork meat, combinations of pork and other food ingredients, and community meals. They show how each category affects ecological values and cultural identity on these islands, and they propose pork food culture as characteristic of a shared maritime culture. Although each island possesses some unique aspects, Lee and Hyun find that pig breeding and pork play a major role in creating a sustainable resource circulation system. As a system to promote community solidarity, there is a rational decision-making process in the butchering and distribution pork, a fair division of labour, and community rituals. The creation of a system of food resource circulation that combines pork with a variety of other ingredients is also found to effectively maintain and sustain the island community. This shows that it is possible to learn from tradition when discussing island sustainability.

Peter Kang focuses on name changes concerning the island that is currently known as Green Island, located around $33 \mathrm{~km}$ off the southeast coast of Taiwan. Kang analyses name changes for Green Island with respect to people who travelled along the Kuroshio current. Green Island had at least four different names up until the end of the Second World War, names assigned by Austronesians migrating to eastern Taiwan along the Kuroshio Current, by Catholics travelling between Ryūkyū and Luzon in the Spanish Philippines in the late$16^{\text {th }}$ and early- $17^{\text {th }}$ centuries, and names originating from shipwreck survivors calling for 
rescue. Kang thus analyses how people moving along the Kuroshio Current have affected the formation of island toponyms and illustrates the cultural influence of people who have moved along the Kuroshio Current. Although the name Green Island has been used since 1949 and has no connection with the Kuroshio Current, some place names on the island and in the seas around it still show the influence of the current. This is especially true for fishing grounds, created mainly by the Kuroshio Current, which are related to islanders' cultural memory. The cultural dynamics of the peoples who have moved along the Kuroshio Current are reflected in the island's changing names. This is true for many other islands along the Kuroshio Current as well, where cultural movement and exchange have played important roles in determining island names and identities and provide important clues to understanding an island community's cultural trajectory.

The aforementioned Kuroshio maritime cultural studies on beliefs, pork food, and place naming highlight the impossibility of understanding any one island's culture and identity simply by studying it in isolation. Data collection and research on Kuroshio islands and their cultures can contribute to a comprehensive and holistic understanding of shared maritime cultures across the Asia-Pacific region. The sea in which the Kuroshio Current flows is not just a geographical unit but also an integration of trajectories for those who live and have lived in the area.

Islands in the Kuroshio Current have undergone great social change under the dynamics of various global powers. As such, this single maritime cultural area has been conceptually segmented and coloured by nationalism. I hope that understanding of the islands' maritime culture will improve through the adoption of oceanic perspectives. The aforementioned studies in this special thematic section thus mark a starting point for such integrated future works on 'the Kuroshio oceanic cultural sphere'.

\section{References}

Heo, N.C., \& Lee, H.J. (2018). Sea deity beliefs of the Kuroshio oceanic cultural sphere: maritime traditions and cultural interaction among Jeju Island, Zhoushan Archipelago, and the Ryukyu Islands. Island Studies Journal, 13(1), 171-184. https://doi.org/10.24043/isj. 55

Kang, P. (2018). The influence of the Kuroshio Current on place-naming on Green Island, Taiwan. Island Studies Journal, 13(1), 185-194. https://doi.org/10.24043/isj.58

Lee, S., \& Hyun, H. (2018). Pork food culture and sustainability on islands along the Kuroshio Current: resource circulation and ecological communities in Okinawa and Jeju. Island Studies Journal, 13(1), 195-208. https://doi.org/10.24043/isj.61 
Hyekyung Hyun 